[JUNE, 1918.]

\title{
BRAIN.
}

PART I, VOL. 41.

\section{THE INTERDEPENDENCE OF THE SYMPATHETIC AND CENTRAL NERVOUS SYSTEMS. ${ }^{1}$}

BY DAVW ORR, M.D., AND LIEUTENANT.COLONEL ROTS, R.A.M.C.

Experiments with bacterial poisons have demonstrated that the central nerrous system can be infected by two paths, the lymph channels and the blood-stream [6]. The lymphatic system of the brain and spinal cord can be infected secondarily to a toxic or microbic invasion of the ascending lymph paths of cranial or spinal nerves, and the phenomena which arise are typically those of a primary inflammation of the fixed tissues. The examination of material from clinical cases, in which toxic absorption from septic foci had occurred along the lymph spaces of peripheral nerves to the nerve centres, confirmed the above results.

When attempts are made to infect the central nervous system by means of an intoxication of the blood-stream a totally different picture is found. In one series of experiments we introduced a capsule containing a broth culture of the Staphylococcus pyogenes aureus into the abdominal cavity of rabbits [8] with the result that definite areas of the spinal cord showed degeneration of the medullated fibres, viz., round the cord margin and on either side of the median septum of the posterior columns. These degenerations were associated with œdema, dilatation of the vessels, and hyaline thrombosis. Inflammatory phenomena amongst the fixed tissues were strikingly little in evidence. In another series of experiments [7] the capsule was placed in contact with the common carotid, and the examination of the brain revealed two types of lesion: (1) Coagulation necrosis of the nerve cells in the cornu ammonis, in the cerebral cortex, and in the amygdaloid nucleus; (2) softening in the stratum moleculare of the cornu ammonis. Here

' This work has been carried on under a grant from the Board of Control. 
again the inflammatory phenomena were reduced to a minimum, except around the softening in the stratum moleculare of the cornu ammonis: but in this situation the proliferation of the fixed tissues was obviously secondary and dependent upon the irritative effects of the degenerative products in the surrounding tissues, and upon the reaction incidental to repair. Dilatation of the vessels, œdema, and hyaline thrombosis were present, and the above lesions clearly resulted from the consequent disturbance of the cerebral circulation.

These two types of infection, lymphogenous and hæmatogenous, are thus easily distinguished from each other. The former always gives rise to an inflammatory lesion which in both the peripheral nerves and in the central nervous system spreads by direct continuity. But the hæmatogenous lesions are much more difficalt to explain, as the consideration of their anatomical distribution in the spinal cord and brain indicates very clearly that in addition to toxicity of the bloodstream there is another factor in play which determines where the toxin shall exhibit its primary effect.

This point is well illustrated by the experiments referred to above. When the abdominal cavity is infected a non-systemic lesion is found in the white matter of the spinal cord. Two areas are involved, the periphery of the cord and the posterior columns. In the cervical and lumbar regions the entire periphery of the cord is affected. In the dorsal cord this.marginal degeneration is limited to the anterior and lateral parts. The degeneration in the posterior columns shows variations at different cord levels. In the lumbar cord it forms a small triangle round the hinder end of the postero-median septum with its base towards the cord margin. In the dorsal cord it forms an inverted $V$ whose apex reaches the middle of the septum while its legs diverge towards the cord margin. In the cervical cord this degenerated area is larger than in the lower regions and forms a narrow column situated in each tract of Goll near the median septum and united to the marginal degeneration. The myelin lesion is maximal in the cervical, and minimal in the lumbar region. It is sharply confined to the above areas and consists in a primary degenerstion of the sheath. With this myelin degeneration there are associated cedema of the cord, proliferation of the perivascular neuroglia, and dilatation of the vessels with hyaline thrombosis. In the grey matter the only morbid change is a very slight degree of chromatolysis of the nerve cells.

When the capsule filled with bacteria is placed in contact with the carotid sheath we find, as already mentioned, coagulation necrosis of 
nerve cells in the cortex, of the lamina ganglionaris of the cornu ammonis, and in the amygdaloid nucleus. There is also an ischæmic softening in the stratum moleculare of the cornu ammonis. Vascular dilatation and hyaline thrombosis are again a prominent feature. When the distribution of the lesions in both series of experiments is examined it is clear that they lie in those parts of the brain and spinal cord which derive their blood supply from the vessels of the piaarachnoid. The implication of the cornu ammonis and the amygdaloid nucleas does not, as might appear at first sight, contradict this statement; for the lamina involuta of the former is penetrated by folia of the pia-arachnoid, while the amygdaloid nucleus is continuous with the grey matter of the temporal lobe. The affected areas therefore possess this point in common that they depend upon the pial vascular system for their nutrition; and it is this special anatomical distribution, to the total exclusion of the central areas, which inclines one to the view that a general intoxication is by no means a satisfactory explanation of the genesis of the lesions. A considerable weight of evidence can be advanced in favour of the view that the sympathetic nervous mechanism may be an important factor in determining at which points a toxin circulating in the blood shall exercise its primary action upon the central nervous system. Our authority for making this statement is derived from the study of certain non-systemic lesions in the cord, and from the anatomy, physiology, and embryology of the so-called autonomic system. Non-systemic lesions occurring in the spinal cord are characterized by atrophy of the myelin sheath and sclerosis. They appear to be dependent on some toxic condition of the blood-stream, which attacks the myelin sheath in certain definite areas by some obscure mechanism. We have studied such lesions in cases of visceral cancer and in Addison's disease; and on account of certain features which they possess in common with the subacute combined sclerosis of the cord, associated frequently with severe anæmia, we propose to inclade this group in the description.

If the spinal cord is examined in cases of visceral cancer a nonsystemic lesion will be found which varies in degree from case to case. As an illustration let us examine in some detail the cord from a case of carcinoma of the pyloric end of the stomach. This case showed a more extensive lesion than is usually found, but in its general features and localization it was typical. The cord lesions in visceral cancer affect the posterior and lateral columns; the fine fibres of the grey matter are rarely implicated and only in advanced cases; and the morbid 
lesion consists in a slow atrophy and absorption of the myelin sheath accompanied by proliferation of the neuroglia. In the posterior columns the atrophic process varies in intensity in the cervical, dorsal, and lumbo-sacral regions. It is most marked, at all levels, round the posteromedian septum and its area of maximum intensity changes frequently. Tracing it from above downward we find that from C1 to C3 it occupies a small area on either side of the posterior third of the septum. From $\mathrm{C} 4$ to $\mathrm{C} 8$, where the lesion is more pronounced than at any other level, it parses forward to occupy a more anterior position, until in C8 and in the upper six dorsal segments the areas immediately adjacent to the anterior third of the septum are most affected. From the level of D6 the area of atrophy progressively diminishes in size from above downwards and is shaped like an inverted $\mathrm{V}$ whose apex is directed towards the commissure and whose legs gradually diverge, on either side of the postero-median septum, towards the cord margin. The lesion at this level is of more recent date than that at a higher level. In shape it resembles closely the acute lesion found in the rabbit's cord after infection of the abdominal cavity. At the level of $L 1$ there is some little degree of myelin atrophy confined to the fibres immediately surrounding the septal vessel and its branches, and from L3 downwards there is practically no change whatsoever.

The atrophic process accompanied by neuroglial proliferation begins round the postero-median septam, and progresses from within outwards. The lesion attains its maximum development between the fourth and eighth cervical segments, and in early cases we have observed that these and the highest dorsal segments are alone affected.

The lesion in the lateral columns is similar in natare to that of the sensory fibres but of less intensity. From C1 to C3 it is situated at the cord periphery and implicates both anterior and posterior cerebellar tracts. Below this level it occupies a more central position amongst the crossed pyramidal fibres and the lateral basis bundles. Similarly to the lesion in the posterior colomns it diminishes in degree from above downwards and disappears almost entirely in the upper lumbar segments.

In Addison's disease the lẹion in the spinal cord bears a remarkable resemblance to that in visceral cancer. It occupies the same position in the posterior columns. The morbid changes are more advanced in the cervical region and diminish from above downwards. They are of a more acute nature, however, and include more of the central portion of the posterior columns; while the histological picture presents certain 
differences indicative of a more profound morbid disturbance. Weigert's method demonstrates that the medullated sheaths in the affected areas are totally destroyed; and in sections stained by Marchi's osmic acid method one finds the adrentitial lymph spaces of the vessels in the degenerate area filled with the products of altered myelin stained jet black. Evidently, in this case, absorption of the altered myelin has not kept pace with its destruction, and injury to the axis-cylinder has in all probability been a contribatory factor to rapid disintegration. There is evidence in other areas of the cord of implication of the axis-cylinder. For example, there are scattered patches of sclerosis in the anterior and lateral regions of the dorsal cord, and one of these has interrapted many fibres of the right crossed pyramidal tract, causing a descending degeneration.

In the lateral portion of the cord there is some degeneration situated at the periphery and extending from the cervical to the lumbar region. This is different from what is found in the lateral area of the cord in cancer cases, but agrees with the results of those experiments in which the medullated fibres round the cord periphery showed primary degeneration. The fine fibres in the grey matter of the upper dorsal and the cervical regions are atrophied to some extent; in the lower dorsal and lumbar segments they are practically intact.

There is another condition in which the spinal cord shows a degeneration similar in character and distribution to the above, though of a more severe nature. Subacute combined sclerosis gives rise to a definite clinical picture, and is frequently associated with severe anæmia. The lesion is more intense than in cases of cancer and Addison's disease, and on that account tends to obscure the pathogenesis, bat an analysis of the morbid features shows that apart from intensity the same morbid process is at work.

The portion of the cord most affected is the mid-dorsal, where there is marked destruction of the white fibres round the entire periphery, leaving the grey matter and the fibres in its immediate environment perfectly normal. The exogenous and endogenous fibres of the posterior columns are affected equally. Above the mid-dorsal region the lesion becomes more limited, that is to say, it is confined to the central portions of the posterior columns, to the two cerebellar tracts, and to the crossed pyramidal tracts. In the cervical region there are also scattered areas of degeneration, a favourite site for them being the direct pyramidal tract and the neighbouring bundles. The destructive lesion is found as high as the upper portion of the medulla; the upper 
limit of the pons, the internal capsale, and the cerebral cortex are perfectly normal. Below the mid-dorsal region the diffuse destructive lesion steadily diminishes in intensity, and in the lumbar region it is practically limited to the crossed pyramidal tract and to the posterior columns. Russell, . Batten, and Collier [10] point out that we are obviously dealing here with a focal destructive lesion and system lesions dependent upon implication of ascending and descending tracts. The morbid process in its early stages is best seen at the margin of a degenerative patch. The myelin sheath first shows swelling, while the axis-cylinder remains normal. Later on, the sheath undergoes degeneration, and is absorbed, the axis-cylinder disappears, and sclerosis supervenes, attended by the ascending and descending degenerations mentioned above; but these are really secondary results. The grey matter, the spinal roots, and the posterior root ganglia are normal. The vessels in the affected area show thickening of their walls.

It is of importance to note that in most of these cases the degeneration of the posterior and lateral columns is most evident in the midthoracic region, and diminishes in degree and extent as the apper and lower limits of the cord are approached. The above-mentioned authors, in discussing the pathogenesis of these lesions, draw attention to their important observation that the distribution of the affection in the white matter is precisely that of the peripheral vessels, the pial supply, and point out how the areas supplied by the anterior median arteries-the anterior horns, adjacent white matter, and Clarke's column-escape.

We have described the above lesions as non-systemic, although it is obvious that in the posterior columns they bear a close resemblance to tabes dorsalis. There are cardinal differences, however, in the primary localization and further spread of the disease which separate it from a true tabes. The term pseudo-tabes might be employed on the clear understanding that the disease is not confined to the posterior columns, but is combined with sclerosis elsewhere.

If we review briefly the type of lesion in the three cases to which we have drawn attention, it is evident that we are dealing with three different degrees of one and the same pathological process. The sitantion of the degeneration is practically the same in all, especially in the posterior columns; and the late involvement of the fibres in the grey horns is a constant feature. In the cancer cases it is evident that the lesion is characterized by a gradual atrophy and absorption of the myelin sheath. So far as our experience goes, there is no evidence of axis-cylinder change, but the possibility of this occurring in other cases 
must be admitted. In the case of Addison's disease the pathogenetic agent is enabled to produce greater damage, for the lesion is not only more extensive, but we find the adventitial lymph sheaths in the posterior columns filled with fatty substance. In addition to this, isolated degenerative patches are found in which the axis-cylinders have suffered sufficient damage to cause a true Wallerian degeneration.

In the subacute combined sclerosis the morbid lesion is even more advanced. In the area of concentration, the mid-dorsal region, the axis-cylinders have been attacked, and the destruction has resulted in ascending and descending degenerations. Above and below the area the lesion is much less acute, and though its limits, above and below, are more extensive than in the cancer cases and in Addison's disease, it is similar in nature. The dissimilarity in extent might be reasonably explained by the fact that the morbid process has acted in a more acute fashion, and its effects have spread farther by diffusion of the noxious agent.

We have already mentioned that these non-systemic cord lesions appear to be caused by some toxic substance in the blood, bat a general statement of this nature does not help us to explain the constant and peculiar situation of the lesions. They form a definite group-which, no doubt, includes more members than we have mentioned-whose characteristics make it reasonably certain that some special factor comes into operation in the pathogenesis. We assume that the myelin is attacked by a poison of some kind, and that this, if sufficiently strong, or in action for a sufficient period of time, can injure the axiscylinder. We have no knowledge relating to the nature of the poison, but the lesions themselves raise an equally important question which is concerned with the mechanism by which these definite areas of the cord are invaded. There are insuperable difficulties in the way of our accepting a "general intoxication" theory without qualification. All the facts are against it. The distribution of the degeneration in the lateral and posterior columns, the localization of the degree of morbid change in the upper part of the cord, the gradual diminution of the atrophic change from above downwards until the lumbar level is reached, and the integrity of the grey matter so richly supplied by the anterior spinal arteries, all make the "general intoxication" theory unacceptable. It may be advanced that the affected areas are composed of fibres whose powers of resistance is less than that of others, but for this assumption we have no foundation in fact. Presumably the poison does not act unaided and indiscriminately, and there are reasons for 
surmising that the sympathetic nervous system is, in all likelihood, the intermediary in determining the localization of the lesions. We propose to bring forward evidence in support of this view, derived from recent work in connexion with the autonomic system, as many points in its anatomy, physiology, and embryology, along with some of its relationships to the endocrinic glands, seem to have a direct bearing on the argament before us. We have no accurate knowledge with regard to the part played by the sympathetic system in the causation of central lesions, bat the probability of its action in this direction should not be denied for the present, in view of its intimate connexion with the spinal cord and vessels. Neuropathology in the past has provided many data of importance regarding nervous function, and the lesions under discussion, lying as they do almost entirely within the realm of the thoracico-lumbar vasomotor system, suggest that the influence of this upon the central nervous system cannot be ignored. Our experiments affected special parts of the sympathetic system, and produced corresponding localized lesions.

The sympathetic nervous system, though intimately connected with the central nervous system, differs from it in many respects. It controls the visceral and involuntary functions of the body and has been termed by Langley the autonomic system. Its autonomy is only relative however; it has close anatomical and physiological relationships with the central nervons system.

Two ganglionated cords ran along the ventral surface of the vertebræ from the atlas to the coccyx, segmentally interrupted by ganglia. Each is divided into cervical, thoracic, lumbar, and sacral portions. The cervical cord contains three ganglia, the thoracic twelve, while the lumbar and sacral portions have four or five each. The upper two or three ganglia of the thoracic cord are usually fused into one called the stellate ganglion.

These ganglia are termed vertebral or lateral : those situated more distally, for example in the cardiac, solar, and hypogastric plexuses, are called pre-vertebral or collateral, and small groups of cells lying more distally still in the course of the nerves before they reach their destinstion have received the name of terminal ganglia.

Each lateral ganglion is connected with the spinal cord by a grey ramus; only those corresponding to the spinal segments between D1 and L2 inclusive are connected to the cord by white rami also. These white rami, composed of medullated fibres, come from cells in the lateral horn of the cord (the intermedio-lateral tract) and conduct to 
the ganghonic cells of the lateral chain. The grey rami are not medullated, they are derived from the cells of the ganglionic chain which they connect with the peripheral organs.

Each white ramus sends off many collaterals and thus is connected with several lateral ganglia. The pre-vertebral ganglia are connected with the spinal cord by the splanchnic nerves, and are concerned entirely with internal visceral organs situated in the abdomen and pelvis.

The thoracico-lumbar connector nerves, that is the white rami communicantes, carry impulses to neurons in the vertebral ganglionic chain which supply (1) motor nerves for the muscles of blood-vessels over the whole body; (2) motor nerves for the musculature of all the sweat glands; (3) the whole pilo-motor system; (4) motor nerves for all unstriped muscle in connexion with structures derived from the segmental duct, that is, the ureter, uterus, and Fallopian tubes; (5) motor fibres to the sphincters of the intestine. The lateral, vertebral ganglia supply motor fibres to the blood-vessels of structures innervated by the segmental nerves, both spinal and cranial, including the central nervous system and the thoracic viscera. The collateral or pre-vertebral chain sends motor fibres to the blood-vessels of the abdominal and pelvic viscera.

There is an afferent system of sympathetic nerves which convey sensory impulses to the central nervous system. They are medullated and pass through the white rami communicantes, and have their trophic centre in the posterior root ganglia from which they run in the dorsal roots to the cord between the levels of D1 and L2.

The existence of vasomotor fibres in the brain has until comparatively recently been steadily denied. The action of adrenalin however has proved the presence of vaso-constrictors in the vessels of the brain, lungs, and heart, although it is admitted that their action is weak, and non-medullated sympathetic fibres have been observed to leave the main mass and proceed along the roots of the spinal cord which they reach by the posterior root especially. From these they pass into the cord membranes to supply the blood-vessels, but none enter the cord itself. Moreover, stimulation of the posterior roots has been observed to cause constriction of the blood-vessels of the dara mater.

The sympathetic ganglionic chain thus appears to be an extensive system of reflexes. ${ }^{1}$ It is supplied with afferent and efferent fibres. From the level of D1 to L2 there is a connecting neuron within the

\footnotetext{
'We use the term " reflex" deliberately here.
} 
central nerrous system-the intermedio-lateral tract-which completes the arc between the afferent and efferent systems, and this fact, to which we shall return, seems to be of practical significance in connexion with the combined lesions in the cord already described. Another important point which must be kept in mind is that sympathetic action is dependent upon the supply of adrenalin. This point also shall receive further consideration.

It is not possible in view of recent additions to our knowledge of the sympathetic system to consider it as an independent entity. It is now known to be intimately connected both anatomically and physiologically with the ductless gland system. In fact, when we come to study the phylogenesis and ontogenesis of the vegetative system it is at once apparent that its relationship with the adrenal bodies is such that the development of each can hardly be considered separately. Phylogenetic and ontogenetic studies prove conclusively that the sympathetic nervous system, the adrenal bodies, and all chromaffin tissue must be considered as one in relation to the blood vascular system; and our reason for going into some detail in this direction is the importance of this relationship upon the cord lesions under discussion.

From animals low down in the scale to mammals, the close association of adrenal bodies with the sympathetic system has been recognized by many workers. In a primitive form of animal life, for example in the Petromyzon, there are two distinct series of bodies. One is represented by small lobulated structures in the wall of the posterior cardinal veins, of the renal arteries, and of the arteries dorsal to the kidneys. They project into the lumen of the vessels and consist of cylindrical or polyhedral cells containing granules which stain black with osmic acid. These are the cortical or inter-renal bodies. The other series-the chromaffin series-extends from the region of the second gill cleft to the tail, and each strip of tissue runs along the arteries and their branches. These structures bear the same relationship to the veins as the cortical bodies and correspond to the medulla of the suprarenals. These paired suprarenals lie in close contact with the ganglia of the sympathetic chain and contain large nambers of chromaffin cells. When we reach the Reptilia we find a closer relationship established between the cortical and medullary elements; and in birds it is still closer, the latter occupying the meshes of the former.

Mamnials alone possess a true cortex and medulla, the latter completely surrounded as a rule. The cortex has the same structure 
as its homologues in the lower vertebrates, and consists of rounded groups or columns of cells containing fat-like granules which stain deeply with sudan III, scharlach red, and become blackened with osmic acid. The cells of the medulla have a great aftinity for nuclear stains, and with chromium salts may assume any shade from a bright yellow to a dark brown. Cells exhibiting precisely this reaction have been found in the carotid body of mammals; and accessory chromaffin substance is found in any part of the body into which the sympathetic system extends, bat especially in connexion with the abdominal sympathetic.

Now physiology teaches us that all chromaffin tissues yield adremalin, or a similar chemical substance, and that the effects produced by this are almost all such as are produced by the sympathetic system. Comparative anatomy shows also that in addition to the medulla of the adrenal body there are numerous scattered bodies of the same nature in close relation to the sympathetic ganglia and nerves throughout the body. The adrenalin passes by the adrenal veins into the general circulation and assists in maintaining the tone of sympathetically innervated muscle and other tissue; and it is interesting to note in this connexion that the cells of the medulla are derived from the cells of the embryonic sympathetic system. Swale Vincent [11]-from whose comprehensive work we have borrowed extensively-affirms "that the cortex is derived from the mesoderm and the medulla from the same blastema as the sympathetic ganglia is now universally conceded." The intimate relationships between the vegetative nervous system and chromaffin tissue is therefore obvious.

If we look more closely into the development of the sympathetic system its intimacy with adrenal tissue from the earliest is clearly demonstrated.

There are two views regarding the genesis of the sympathetic nerrous system, one that it is of mesodermal origin, the other that it is derived from the ectoderm. In a recent and important paper by Bruni [2] the whole question is revived and several facts of fundamental importance added. Observations in the higher vertebrates, and especially in birds, leave no doubt that sympathetic radiments appear before there are any visible signs of rami communicantes connected with them. Bruni is of the opinion that the first limiting layer is derived from the mesoderm. Near the place where the segmental vessels leave the aorta and at the cranial extremity of the mesonephros small cellalar mesodermal accumulations appear. In a short space of 
time these, at first arranged segmentally, are gathered into a continuous column and rapidly extend cranially and caudally, forming a dense protoplasmic trabecula. Such formations are particularly evident in the thoracic and abdominal regions. Two other facts deserve special notice. One is that in this mesodermal rudiment droplets of a substance develop possessing a strong affinity for hæmatoxylin. Secondly, simultaneously with the formation of these droplets, or shortly afterwards, neurocytes appear in the lateral branch of each spinal nerve-at least in the thoracic region-which accumulate at a point in the nerve least distant from the mesodermal rudiment and are projected towards it. Bruni is firmly of opinion that the mesodermal radiment of the sympathetic is originally independent of the ectodermal portion, and adds that the former exerts an attraction on the ventral branch of the spinal nerve.

In a very short period of time the mesodermal and ectodermal rudiments become fused, and as development proceeds some of the trabeculæ (mesodermal) assume intimate relationships with the endothelium of capillaries lying laterally and ventrally to the aorta. The mesoderm then becomes rarefied, shows segmental swellings, and a few cells like posterior root ganglion cells. It is important to note at this stage that the mesodermal rudiment spreads laterally and in front of the aorta in the region where the cœliac and aortico-abdominal plexuses develop. A visceral ramus of each ventral spinal nerve now enters the mesodermal rudiment in the thoracic region: in the abdominal region part only enters, while the remainder expands in the region of the coeliac and abdominal plexuses to establish connexions with the mesodermal polynucleated protoplasmic trabeculæ.

From this stage onwards nerve fibres penetrate the trabecular mass freely, which thus becomes linked up by rami communicantes to the spinal nerves. With the advancement of development the polynucleated masses become more scanty, save in the region of the fature coeliac and abdominal plexuses where they undergo a decided increase. These masses are permeated by nerve fasciculi, and are in intimate contact with the endothelium of the large capillaries. Still later in development the mesodermal rudiment, having attracted the fibres and cells of the spinal nerve destined to supply the true sympathetic elements, and having established connexions with the endothelium of the vessels, in part becomes transformed into a fibro-cellular cord, while a portion in the region of the coliac and abdominal plexuses develops into the chromaffin formations which constitute the paraganglia and the medullary substance of the suprarenals. 
There are some special points in connexion with the cervical sympathetic which deserve notice. Here the primary limiting layer gradually becomes less intimate with the spinal nerves and establishes connexions with the cranial nerves, especially the tenth, which in manmals contributes cellular elements early to the sympathetic cord. The superior and middle cervical ganglia are derived from a nonsegmented cord, are not supplied with neurocytes by spinal nerves metamerically, but by elements which come up from the thoracic region and down from the ganglion nodosum of the vagus nerve. This is an important point, and Bruni mentions it in relation to the observations of His, Kuntz, and Abel, according to whom elements from the ninth and tenth cranial nerves supply supra-diaphragmatic plexuses of the sympathetic, especially the cardiac plezus and ganglia. Studies in comparative anatomy show that as we ascend the animal scale the components of the cervical ganglion tend to come progressively less from the spinal nerves and more from those of the sympathetic portion of the vagus.

An examination of the data obtained from a stady of the sympathetic system provides as with certain facts which, if they do not afford a complete explanation of the lesions in the conditions mentioned above, at least are of sufficient importance to merit attention, and suggest a problem worthy of further investigation. There can be no doubt that the localization of these lesions in the central nervous system is not caused in a haphazard fashion in the course of a general intoxication. Such a definite localization as we have seen in the area of pial supply can be, in the cord at least, correlated with the spinal distribution of the thoracico-lumbar sympathetic system. This we have seen possesses central neurons (the intermedio-lateral tract) which send efferent fibres, preganglionic fibres, to the ganglionic chain, and receives afferent fibres, all, or nearly all, of which run into the posterior root gangliatheir trophic centre-and onwards into the cord by the posterior roots without entering into direct relationships with the sympathetic ganglia. The stimulus which these afferent fibres communicate must reach, therefore, the central nervous system before transmission to the periphery. We must conclude from this that in the sympathetic ganglionic chain there is no true reflex arc, or in other words that it cannot subserve reflex action without the intervention of the cerebrospinal axis. But experiment has shown that in the sympathetic chain there are pseudo- or axonal-reflexes in which no afferent fibre is involved, and when a stimulus is applied to an axis-cylinder it can be 
transmitted by one of its collaterals to another cell or another ganglion as each preganglionic fibre sends collaterals to many ganglia.

Langley's work shows, however, that the sympathetic ganglia cannot maintain tone apart from the central nervous system, and the consensus of opinion seems to be that the ganglia merely act as reinforcing centres for stimuli from the central axis. But in the afferent and efferent systems of the spinal sympathetic centres and their connexions with the chain of ganglia we have all the elements of a true reflex arc, and the distribution of the spinal cord lesions is practically within the realm of this arc.

The involvement of the cervical segments does not contradict the argument, for, though the thoracico-lumbar mechanism lies within the limits of D1 and L2, it should be remembered that the lower half of the cervical cord is supplied by the ramus vertebralis composed of grey fibres derived from the stellate ganglion, which consists in a fusion of the first two or three thoracic ganglia. There are strong anatomical reasons, therefore, for the hypothesis that some disturbance of the sympathetic system may be held responsible for the localization of the atrophic and sclerotic changes, as they are only found in the vascular areas known to be under sympathetic control, i.e., those supplied by the pial vessels.

It is difficalt to anderstand why the lower cervical and upper dorsal regions are most affected, and we have no explanation to offer. In all probability this problem, amongst others, involves an elucidation of the complex reflex paths in the sympathetic chain. Obviously these are not so direct as those in the peripheral spinal nerves, a point well exemplified by such common examples as the complex course of the dilator fibres of the pupil, the referred pain of visceral disease, and the unilateral malar flush so frequently seen in pneumonia. That the sympathetic system, however, comes into action in physiological and pathological conditions in the central nervous system seems to find additional support from the spinal cord lesion found in Addison's disease, whose syndrome is that of adrenalin inadequacy. Here we have muscular hypotonus and fall in blood-pressure generally, from which one can argue vaso-dilation in the pial sapply of the cord.

We would suggest, therefore, that the lesions we have described are due to some interference with the thoracico-lumbar sympathetic reflex, caused possibly by pathological stimuli, or by the absence of substances which maintain its balance. This results in dilatation of the pial vessels whose permeability is thas increased. Hence the diffusion of 
noxious substances amongst the nerve fibres is facilitated, resulting in a progressive and ever-widening circle of atrophy and sclerosis.

If we are correct in the assumption that the organic cord lesions we have described are the result of some disturbance of the sympathetic system, then it would seem equally legitimate to suggest that certain so-called functional disturbances of the central nervous system may owe their origin, or if not that, their tendency to recurrence and permanency to the same mechanism ; for, as we have seen, the sympathetic system is intimately linked ap with the central nervous system, has no true autonomy, and there are anatomical paths which provide for a constant interaction between both.

Stimuli must be passing constantly from the sympathetic to the central nervous system, as there are special sense organs in the viscera and a definite sensory afferent path; and although these stimuli do not pass the threshold of consciousness normally, one cannot deny that they exercise physiological effects, knowing that under abnormal conditions they evoke pain. We must admit, therefore, that the stimuli from the sympathetic system exert an influence upon the brain under normal conditions, and play an important part in mental activity. In all probability stimuli coming from the vegetative organs to the brain, where they excite bodily sensations and instincts in consciousness, are of as great importance as those derived from the external world. And there is another point which must be taken into consideration. The relations which the sympathetic chain has with the vascular system and the ductless glands add very considerably to its functional importance in physiological and pathological conditions, so that in considering its influence on the central nervous system we have not only the effect produced by stimali to take into account, but.that through the vascular and endocrinic systems as well.

The precise relationship of the vascular system to the nerve-cells, and the mechanism by which the functional activity of these highly specialized elements is controlled, is still very obscure. Some modern workers are of opinion that the neuroglia plays some part in the process, and though the views advanced are not yet quite convincing, still with our knowledge so scanty as it is at present we must give them due consideration.

Achúcarro [1] considers that all the protoplasmatic neuroglia fanctionates as an interstitial gland which acts on the nerve elements and on the blood, contributing by means of specisl hormones to the endocrinic harmony of the organism. This view is based to a large 
extent on the presence of a foot-like process at the peripheral end of the neuroglia fibre which forms a connexion with the blood-vessels, and on certain embryological data.

The primitive neuroglia is represented by the ependyma, and, as development proceeds, the "neuroglial-ependymal" elements pass into the depth of the tissue. These embryonic neuroglial cells develop more rapidly in those ganglia which have acquired the greatest morphological and physiological importance. As the central nervous system thickens, and acquires a rich vascular network, the connexion between the neuroglia and blood-vessels becomes progressively more intimate, and Achúcarro advances this in support of his hypothesis that the neuroglia is a glandular vascular system. Cajal also is of opinion that there is a nutritive relationship between the neuroglia and the nerve-cell. When the nerve-cells are nourished from the ependymal space, they remain in that situation, and are unipolar; but when the vascular network is established, and the neuroglia becomes autononous, then the neurons migrate, and become multipolar. It would appear from these authors that the neuroglia, under normal conditions, neutralizes noxious substances coming from the vessels, and destroys catabolic products from the nerve-cells, thus constituting a constant chemical rejuvenator, to a certain extent, in the substance of the nervous system. Achúcarro then pushes his theory still further, and applies it to the mechanism of the emotions. Granted, he says, that there is an indirect connexion between the nerve-cells and the vascular system, the neuroglia considered as an internal secretory gland could take part in the emotional mechanism. Recent researches, he continues, especially those of Cannon, have shown that in emotion not only is there a dynamic repercussion transmitted from the nerve elements, but there is also a true humoral repercussion expressed by an increase of glucosides and adrenalin in the blood, indicating hyperactivity of the adrenals. In this connexion Crile has drawn attention to an increased activity of the thyroid in emotion. Achúcarro thinks, therefore, that he is justified in advancing the theory that the protoplasmatic neuroglia, on account of its structure, relationships with the vascular system, and intinacy with the nerve-cells, can at certain times of nervous activity pour hormones into the blood which provoke other endocrinic manifestations with which emotionalism is associated.

Lugaro [3], criticizing Achúcarro's work, draws attention to its psycho-physiological nature in relation to the somatic humoral mechanism of the emotions. He points out, however, that emotion can 
be awakened purely dynamically through the nerve paths. Emotional phenomena take place with such rapidity that only nervous transmission from the brain to the periphery, and vice versa, could bring them into play. Were the emotional mechanism entirely dependent upon internal secretion, the emotion. would occur slowly and last an excessive time. Lagaro notes that all the phenomena manifested during an emotion, or immediately afterwards, are not an integral part of its mechanism. It is conceivable that they could be for the most part purely collateral effects, devoid of any biological utility and perhaps, by their overflow, even damaging. He suggests the investigation of the relationships between certain conditions of disturbed hormonic equilibrium and the variations which they induce in the excitability of the nervous elements, especially those of the visceral system. Possibly for each type of disturbed equilibrium there may be an excessive facility or an abnormal inhibition of certain emotions. For example, there are the anxious apprehension in Graves's disease, and the phlegmatic character in hypothyroidism. An ideal affective equilibrium, ideal character, and a perfectly normal emotional state only exist with perfect hormonic equilibrium; and if lively emotions, especially when prolonged, disturb the hormonic belance they acquire greater importance inasmuch $\mathbf{8 s}$ an abnormal emotional state arises through disturbed humoral equilibrium. It is along such lines that Lugaro thinks we shall arrive at a knowledge of the physiology and pathology of the affections, and perhaps even find a rational somatic therapy of the dysthymiæ.

There is an interesting paper by Von Monakow [5] in which he enters a plea for the material basis of the sentiments and emotions. He is of opinion that the moterial basis of the sentiments ought to be regarded as chemical, not as anatomical or morphological. The chemistry of the blood and endocrinic glands comes into play as a varying and most important factor. The chemical composition of the blood is of cardinal importance for the sentiments; for sensution, motion, and orientation in time and space, it is-within physiological limitsof less importance. Even as low down in the animal scale as Vermes, there exists, in the cells of Leydig, an organ homologous with the endocrinic glands. In the human foetus there are at the second month indications of the suprarenal capsule, which are intimately connected with the sympathetic ganglia; and the extreme sensitiveness of the sympathetic to pharmaco-dynamic action has been demonstrated by adrenalin, pituitrin, cocaine, nicotine, atropine, \&c. Cannon and 
Asher have shown that psychic excitement determines, through the sympathetic paths, a hypersecretion of adrenalin into the blood. The internal secretory glands, therefore, influence the nervous system in general, and the sympathetic in particular, and so provide a diffuse mechanism which regulates the vegetative or instinctive life of the organism. Thus the way is paved for elective chemical actions to create, on the exhibition of special stimuli, a favourable or inhibitory influence, and determine, amongst a conflict of stimuli, the appearance of a certain sentiment. Von Monakow then proceeds to discuss the epochal development of the sentiments in man and his conclusions are of the greatest interest. He says that, broadly speaking, the evolution of the sentiments cannot be placed in clear relationship with the phases of anatomical development. All we are justified in saying is that the primordial sentiments ought to have a more solid organic basis than those of later growth, and therefore under morbid conditions their resistance to the tendency to dissolation is greater. He supports the psycho-analytical school who ascribe great importance to the psychogenetic factor in the functional psychoses, neurasthenia, obsessions, and hysteria, but tempers their views by an unqualified admission of somatic factors. While he readily grants the frequent incidence of degeneration as a predisposing factor, great stress is laid upon the biochemical, organic, or somatic factor, that is to say, one absolutely apsychic. For example, moral trauma, severe psychic conflict, unsatisfied strong instinctive tendencies, disturb, through the sympathetic system, the endocrinic glands; and thus changes arise in the blood, which, combined with prolonged psychic stimuli, create nervous instability, resulting in neurasthenia, hysteria, phobias, and hypochondriasis.

"Evidently then," as Lugaro remarks in his criticism [4], "the nervous system and the endocrinic glands act as one under certain circumstances and constitute the basis of many changes in normal psychic life; both are naturally more operative in certain pathological states, which psychologists have tried to explain by fantastic hypotheses. Between moral trauma which arises from a psychic cause and its psychopathic effects there are a series of phenomena which no doubt come under the term 'unconscious.' But the 'unconscious' is not necessarily that of the psycho-analyst, psychic unconscionsness; it is conceivably the result of chemical phenomena as unconscious and apsychic as any other."

The psycho-neuroses of the war provide an ample field for the application of all the above data, and demonstrate conclusively how 
INTERDEPENDENCE OF THE SYMPATHETIC AND NERVOUS STSTEMS, 19

disturbance of the sympathetic mechanism, of the endocrinic glands, and morbid emotional conditions, combine to bring about pathological psychic and nervous phenomena. Doubtless these three factors do not act separately. From their physiological intimacy we can hardly escape from the conclusion that all three act together.

Pathogenesis is invariably a difficult problem and especially so in the case of psychoneuroses. As Pighini [9] points out in his discussion of the clinical symptoms and pathogenesis of emotional psychoneuroses, we still know little of normal psychic processes, and of their connexion with other organic processes in the body. The physiology of pleasure, pain, and of the emotions generally shows us, however, that these psychic states are associated constantly with somatic repercassions which are maintained especially by the sympathetic nervous system; but much obscurity exists regarding the manner and path of conduction by which these come about. Pighini is an adherent of Beohterew's view, that in the cortex there are so many successive sensory-motor regions with psychic functions. Each of these regions consists in a receptive centre which is in intimate functional and anatomical connexion with a neighbouring efferent centre, thus forming an organic neuropsychic unity, e.g., optico-motor, acustico-motor, tactile-motor. Sympathetic centres are intimately connected 'with the above and take part in all psychic and psycho-sensorial processes, and thus it is easily conceivable how the sympathetic system becomes involved in disturbed neuropsychic activity by direct transmission from the original site of injury in the sensory motor cortex. For example, the hyperexcitability of the cortical visual or auditory zones, induced by shock, may be diffused to the limiting efferent regions and onwards to the inferior centres in the mesencephalon, medulla, and cord. Hence there arise dilatation of the pupils, nystagmus, cardio-vascular and vaso-motor phenomena, and other symptoms.

The more extensive the neuropsychic zone excited by emotional trauma is, the more accentuated and complex is the morbid repercussion in the sympathetic sphere. These are always more or less accentuated, and are an integral part of the syndrome of traumatic psychoneurosis. The purely psychic symptows of stupor, acute confusion, hallucinatory delirium, excitement, and exaggerated emotional tone come on as a rule before the somatic symptoms due to involvement of the sympathetic and endocrinic systems; and Pighini is of opinion that this implication assumes, secondarily, the preponderating part in the morbid process and prevents recovery of the disturbed central function. 
The somatic symptoms, therefore, are worthy of the most minute examination, seeing that they may prove to be the key to the correct interpretation of the morbid state.

In regard to the sympathetic system the most prevalent signs are those of hypofunction. It must be granted, however, that it is often a difficult matter to decide whether the disturbance is due to hypofunction of one system or hyperfunction of its antagonist. For example, in a case presenting dilatation of the pupil and tachycardia one has to determine whether these depend upon heightened tone of the sympathetic or diminished tone of the antagonist third or tenth nerves. Pharyngeal and laryngeal anæsthesia, paresis of the vocal cords, tachycardia, asthma, frequent vomiting, the absence of the oculo-cardiac reflex and its inversion, all point to vagus hypotonia; while bladder trouble points to involvement of the pelvic nerve.

There are other symptoms indicating involvement of that part of the sympathetic in close relationship with the endocrinic glands. These are dermographism, hyperidrosis, epigastric impulse from the arorta, exophthalmic goitre, and erythromelalgia. Tremor and clonism accompanied by tachycardia, marked asthma, slight hyperthermia, hyperidrosis, and psychic hyperirritability are common. Pighini attributes those symptoms to endocrinic disturbence, and is inclined to give preference to an altered functional state of the thyroid gland. He has found that the thyroid gland reucts readily to sympathetico-cortical trauma, and, having undergone change in function, in turn it induces morbid complications amongst other units of the complex endocrinosympathetic system. This inevitably leads to a reduction of hormone influence and consequently antonomic hypotonia, whose symptons amongst others are tremor, Addison's disease, Raynaud's disease, emotional hyperidrosis, diabetes mellitus, and angioneurotic eruptions. All these conditions have been observed to follow violent mental suffering.

There are certain neurological conditions incidental to war wounds, such as trophic disturbance in limbs, osseous and muscular atrophy, hypertrichosis, hyperidrosis, œdema, hypothermia, anæsthesia, paræsthesia, paresis, causalgic pain, and other symptoms which are not referable to lesions of the sensory or motor nerves, but rather to concomitant sympathetic disturbance. These symptoms according to Pighini are true traumatic tropho-neuroses of reflex origin. It would seem therefore that the function and conductility of sensory and motor nerves can be injured by vasomotor changes. 
From all the above it is quite evident that there is sufficient justification for the suggestion that the sympathetic nervous system, though in physiological control of the involuntary functions, plays a mach greater part in central nervous processes than has been previously admitted. However one may look at the problem, certain facts emerge which prove the close interdependence of the vegetative and central nervous systems.

The situation of the experimental lesions in the cord and brain noted above supply us with this fact, that these are the result of disordered nutrition and occur in the regions of the central nervous system whose vessels are under sympathetic control, that is, in the area of pial supply; and the remarkable distribution of the spinal nonsystemic lesions in the three clinical entities considered affords additional evidence of the operation of the sympathetic factor. At least one must attach no small significance to this fact, that these lesions in the cord occur within, and attain their moximum intensity in the upper part of, the spinal area from which the white rami are projected to the sympathetic chain, and pass the bounds of this, area to a slight extent only. But when we come to study the embryology of the sympathetic system and its intimacy with the endocrinic glands, and their joint physiological effects upon the central nervous system and vice versa, our prior arbitrary division of these into separate organs -in the physiological sense-becomes manifestly absurd; and the clinical evidence substantiates this view.

It is apparent therefore that in nervous diseases, and in those especially which concern the cerebrum, we must in future study not only the more prominent symptoms dependent upon disturbed function of the central organ, bat also the collateral symptoms arising from disturbance of all the peripheral organs intimately connected with it. Anatomy, physiology, embryology, psychology and clinicial neurology indicate clearly that the problem cannot be solved by a narrower programme.

\section{BIBLIOGRAPHY.}

[1] Acrúcarro, N. "De l'Évolution de la Névroglie, et Spécialement de les Relations avec l'Appareil Vasculaire." Reviewed in Rivista di Patologia Nertosa o Montale, 1917, vol. xxil, p. 321.

[2] Bront. "Appunti sullo Sviluppo del Sistema nervoso simpatico negli Amnioti." Archivio per le Scienre Mediche, 1917, vol. xl, p. 146.

[8] Lболво. Rivista di Patologia nerebsa e mentale, 1917, rol. mii, p. 323.

[4] Idem. Rivista di Patologia norvosa e mentale, 1917, vol. xxii, p. 368. 
[5] vow Mosıkow. "Gefuhl, Gesittnng und Gehirn," Correspondonzblatt filr Schweizer Aorste, 1916, vol. xlvi, p. 929.

[6] OrR and Rows. "Lymphogenous Infeotion of the Central Nervous System," Brain, 1914, vol. Ixxvi, p. 271.

[7] Idem. "Further Obeervations on Experimental Toxi-Infection of the Central Nervous System," Brain, 1917, vol. ચl, p. 1.

[8] Idem. "Furtber Observations on the Influence of Toxins on the Central Nervous System," Proc. Roy. Soc. Hed., 1914, vol. vii, p. 21.

[9] Pignin. "Contributo alla Clinica e Patogenesi delle 'Psiconenrosi emotive' osservate el Fronte," Rivista Sperimentale di Freniatria, 1917, vol. rlii, p. 298.

[10] Russell, BatThy, and Colligh. "Subacute Combined Degeneration of the Spinal Cord, Brain, 1900, vol. xxiii. p. 39.

[11] Swale Vincent. "Internal Secretion and the Ductless Glands," London, 1912. 